\title{
A Study of First Year Students Attitude towards HIV and AIDS
}

\author{
Geraldine J. Kikwasi ${ }^{1}$, Sophia R. Lukwale ${ }^{2}$ \& Eleuther A. Mwageni ${ }^{3}$ \\ ${ }^{1}$ School of Architecture, Construction Economics and Management, Ardhi University, Dar es Salaam, Tanzania \\ ${ }^{2}$ Library Services, Ardhi University, Dar es Salaam, Tanzania \\ ${ }^{3}$ School of Spatial Planning and Social Sciences, Ardhi University Dar es Salaam, Tanzania and Tanzania \\ Commission of Universities, Tanzania
}

Correspondence: Geraldine J. Kikwasi, School of Architecture, Construction Economics and Management, Ardhi University. P.O. Box35176, Dar es Salaam, Tanzania. Tel: 255-22-277-5005.

Received: March 2, 2017 Accepted: April 3, 2017 Online Published: April 17, 2017

doi:10.5539/gjhs.v9n7p117 URL: https://doi.org/10.5539/gjhs.v9n7p117

\begin{abstract}
Introduction: Attitude towards HIV and AIDS has been a concern in a number of researches undertaken in the area of HIV and AIDS. Attitude towards HIV and AIDS has two dimensions mainly positive and negative that influence stigma and discrimination towards People Living with HIV and AIDS (PLWHA). The objective of this paper is to determine students' attitude towards HIV and AIDS when they start university life.

Method: The study has employed a longitudinal study design in which data was collected in two phases. This paper presents the results of phase I with the population of the study being all $1^{\text {st }}$ year Ardhi University undergraduate students 2011/12. A sample size of 625 students was determined by using Survey System Package available free on the internet. Stratified random sampling was employed whereby students were categorized into schools and selected proportionately by sex. Data was collected through literature review and questionnaires and analysed using Statistical Package for Social Sciences (SPSS) software package version 20.0.

Results: Results of the study reveal that a relatively high number of students exhibits negative attitude towards PLWHA and to other attitudinal indicators. Within gender, negative Attitude towards HIV and AIDS was noticeable in male compared to female though the difference was not statistically significant. Across schools, School of Architecture and Design (SADE) has a relatively high number of students with negative attitude towards HIV and AIDS of all schools and, generally, the difference in positive and negative attitudes across schools was statistically significant.
\end{abstract}

Conclusions: Studies reviewed disclose negative attitude towards PLWHA in varying aspects at considerable levels. The present study also concludes that significant levels of stigma and discrimination against PLWHA still exist among students.

Keywords: HIV and AIDS, Attitude, Tanzania, PLWHA, Students, Ardhi University

\section{Introduction}

The HIV and AIDS infection has existed for about 40 years. There have been various efforts at international and national levels to combat the infection which have led to decline in HIV prevalence. This promising information is reported in UNAIDS Fact sheets (2015 \& 2016) at global level and (TACAIDS et al.., 2008 \& 2013) at national level. One of the areas which researchers have identified that needs the attention of those who are on the battle ground is attitude towards HIV and AIDS. Others are HIV and AIDS knowledge and risky behaviours.

Attitude towards HIV and AIDS is a main focus of this study because it is closely associated with stigma and discrimination. URT (2013) identify stigma and discrimination as one of the challenges to HIV prevention in the area of HIV testing and counseling. Several researchers (Kuete et al.., 2016; Ranjan et al.., 2015; TACAIDS et al.., 2008 \& 2013; Hayyawi at el, 2010; Lohmann et al.., 2009; Amo-Adjei \& Darteh, 2013; Movahed \& Shoaa, 2010; Rahnama et al.., 2011; Unnikrishnan et al.., 2010; EAC/EALP, 2010) have assessed attitude towards HIV and AIDS, stigma and discrimination using various indicators. Collectively, findings of these studies disclose the existence of negative attitude towards HIV and AIDS among respondents at varying levels. 
In Tanzania and perhaps in the region there is no study that has documented students' attitude towards HIV and AIDS immediately when they join universities with the purpose of making comparison when they are in their third year. This study attempts to fill such gap. The purpose of this study is to determine students' attitude towards HIV and AIDS at the time when they join the university, specifically to determine the following:

- students attitude towards people living with HIV and AIDS

- influence of gender on the attitude towards HIV and AIDS

- influence of the field of study on the attitude towards HIV and AIDS

To achieve these objectives, the study tries to answer the following questions:

- What is the attitude of students towards PLWHA?

- What is the influence of gender on the attitude towards HIV and AIDS?

- What is the influence of the field of study on the attitude towards HIV and AIDS?

\section{Review of Literature}

\subsection{Overview of HIV and AIDS}

Over the years the HIV infection has been a threat as well as challenge particularly in the area of cure and prevention. The first cases of AIDS in Tanzania were reported in Kagera Region in 1983; by 1986 all regions reported the epidemic (TACAIDS et al.., 2008). By the end of 2012, TACAIDS et al. (2013) report that the national HIV prevalence for adults aged $15-49$ was $5 \%$ comprising of $6 \%$ and $4 \%$ for women and men respectively. The UNAIDS Fact Sheet (2016) reveals that by the end of 2015 globally, 36.7 million people were living with HIV; 2.1 million people became newly infected with HIV; and 1.1 million people died from AIDS related illness. The UNAIDS Fact Sheet (2016) also reveals that the most affect region is East and Southern Africa of which Tanzania is part. Sub-Saharan Africa with only 10\% of the world population had 19 million people living with HIV; 0.96 million people became newly infected with HIV; and 0.47 million people died from AIDS related illness (UNAIDS Fact Sheet, 2016). In Tanzania it is estimated that over 2.0 million people are living with HIV/AIDS (TACAIDS et al.., 2013). Globally, UNAIDS Fact Sheet (2016) reveals that 78 million people have become infected with HIV since the start of the epidemic out of which 35 million died from AIDS-related illnesses.

UNAIDS Fact Sheet (2016) reports decline of new infection by $6 \%$ globally and $14 \%$ in East and Southern Africa from 2010. In Tanzania, TACAIDS et al. (2008) and TACAIDS et al. (2013) disclose a decline in HIV prevalence from $6 \%$ to $5 \%$. Similarly, HIV prevalence has also modestly declined among women, from 7 to $6 \%$, and among men, from 5\% to $4 \%$ in the year 2013 (TACAIDS et al.., 2013). The decline in HIV prevalence at international, regional and national levels is a result of efforts done in areas of counseling and testing services, HIV prevention, care, and treatment.

\subsection{Attitude towards HIV and AIDS}

Attitude towards HIV and AIDS has been assessed by a number of researchers using various indicators. Most of these studies focused on attitude of individuals or students towards people living with HIV and AIDS (Kuete et al.., 2016; Ranjan et al.., 2015; TACAIDS et al.., 2008 \& 2013; Hayyawi et al.., 2010; Lohmann et al.., 2009; Lau \& Tsui 2005; Zhang et al.., 2008). Collectively, some of these include:

- attitude of students vis-a-vis of friend/classmate infected of HIV/AIDS;

- students' attitude towards people living with HIV and support of students towards HIV/AIDS matters;

- $\quad$ agree to care for HIV-positive patient;

- continue with marriage plan if partner is found to be HIV positive;

- eating with an HIV-positive individual;

- sitting beside an HIV-positive individual in a bus,

- working with an HIV-positive individual;

- keeping a secret for HIV infected family member;

- avoid making physical contact with PLWHA;

- all infected medical staff should be dismissed;

- PLWHA are merely receiving the punishment they deserve;

- I will stay away from PLWHA; 
- $\quad$ PLWHA should not have the same right;

- willingness to buy fresh vegetables from a market vendor who had the HIV; and

- whether a female teacher who has HIV but is not sick should be allowed to continue teaching.

Other indicators assessed in these and other researches are:

- $\quad$ pre-marital testing for HIV to be compulsory and there should be employment opportunity for HIV infected people, willingness to inform their partners or family if ere diagnosed positive for HIV infection (Rahnama et al.., 2011);

- attitude towards negotiating safer sex and attitudes towards condom education for young people (TACAIDS et al.., 2008 \& 2013; Kopele \& Shumba, 2011);

- background characteristics (age, education, sex, wealth index, religion, student's major, ethnicity, marital status, place of residence and region) (Amo-Adjei \& Darteh, 2013; Movahed \& Shoaa, 2010; Rahnama et al.., 2011; and Unnikrishnan et al.., 2010)

- $\quad$ avoidance of condom usage between partners HIV (Kuete et al.., 2016);

- $\quad$ willingness to get tested for HIV (Unnikrishnan et al.., 2010; Kopele \& Shumba, 2011);

- $\quad$ using condom (EAC/EALP, 2010 and TACAIDS et al.., 2008 \& 2013);

Researchers have established attitudes towards HIV and AIDS at varying levels. The presentation of results among authors ranges from negative to positive attitudes to the percentage of respondents who were in favour or not of the proposition listed or both. Lohmann et al. (2009) determine that teachers over 40 years of age had more positive attitudes than those aged 30-39 years. Ranjan et al. (2015) reveal that more than 50\% women of migrant workers had positive attitude towards people living with HIV and AIDS. Rahnama et al. (2011) disclose that only $19.5 \%$ of all the students stated that they will inform their partners or family if they were diagnosed positive for HIV infection and only $43 \%$ were willing to care for HIV infected person in their own house. Kuete et al. (2016) establish that $45 \%$ of Chinese medical students compared to $36 \%$ of foreigners preferred to avoid condom use after HIV testing; about $29 \%$ of Chinese medical students prefer to stay away from classmate or colleague infected with HIV while $24 \%$ of foreigners thought it was unwise to be close to HIV infected person. Tavoosi et al. (2004) found that negative attitudes toward HIV-infected individuals were common such that $46 \%$ of students thought that a student with the disease should not be allowed to enter an ordinary school, $35 \%$ of the students stated that they prefer not to sit in a class near an HIV positive student and $23 \%$ of students indicated that they would not shake hands with an HIV-positive person if they knew about his or her status. The work of Unnikrishnan et al. (2010) reveals a moderate positive attitude of the general public toward PLWHA with about $45 \%$ stating that they would dismiss their maid on finding out her HIV positive status and 54\% were willing to undergo the HIV test. The EAC/EALP (2010) assessed student attitudes towards HIV and AIDS on using condoms and determined that 9 out of 10 both female and male students believe that female can insist on the use of condoms before having sex with a partner other than her husband, over $80 \%$ of both male and female students believe that there are circumstances where a man can insist on condom use before having sex with a woman other than his wife, and of those who had penetrative sex $78 \%$ and $57 \%$ male and female students respectively successfully managed to refuse sex without condoms. The study by Kopele \& Shumba (2011) found that $41 \%$ of the participants had never taken an HIV test but have involved in sexual activities and a number of them engaged in unsafe sex.

Among the challenges in HIV prevention and control are stigma and discrimination. People with negative attitude towards HIV and AIDS tend to stigmatize and discriminate those who are infected. Stigma and discrimination has an adverse impact on people's willingness to disclose their HIV status as well as testing which contribute to spread of the infection. TACAIDS et al. (2013) concludes that stigma and discrimination are still wide spread among Tanzania adults. TACAIDS et al. (2013) further determines that only $25 \%$ of women and $40 \%$ of men expressed accepting attitudes on all four standard indicators used to measure stigma. People who are infected including their relatives and friends tend to hide their HIV status for the fear of being discriminated. Katahoire \& Kirumira (2008) disclose that students who are HIV-positive or who suspected they could be, responded in differently ways such as withdraw from social relations, stopping attending classes and some did not pay much attention to their academic work. Zhang et al. (2008) determine a high proportion of college students having both stigmatizing attitudes toward PLWHA and misconceptions about HIV/AIDS transmission routes. Similarly, Lau \& Tsui (2005) determine that a good number of respondents exhibited discriminatory attitudes in at least five out of the 20 relevant items. Unnikrishnan et al. (2010) disclose that discriminatory attitude toward HIV positive people among respondents with less than secondary school education agree or believe that the infected deserve to suffer, dismiss 
a HIV positive maid from her duties, they hesitate to sit next to a HIV positive person in the bus, infected spouse should be divorced, and are willing to get tested for HIV.

\section{Methods}

The study was conducted at Ardhi University Campus located in Kinondoni Municipal, Dar es Salaam, Tanzania. The area was chosen so that results could be used directly for planning purposes to control HIV and AIDS within the University. The study has employed a longitudinal study design in which data was collected in two phases. It involved observation using similar measures repeatedly to a selected sample of the same population to determine trend. Phase I of the study was carried out in late 2011 and Phase Two was carried out in 2014. This paper presents the results of Phase I.

The population for the study in Phase I was 1074 which consisted of all $1^{\text {st }}$ year ARU undergraduate students of the academic year 2011/12. The sampling unit was all first year students. A sample size of 625 students was determined by using Survey System Package available free on the internet. This implies that the study required a total of 625 respondents to obtain statistically representative data at 95 per cent confidence interval and 4 per cent confidence level. The selection of 625 students for inclusion in the study represented $68.5 \%$ of the first year students admitted in 2010/11 academic year. Stratified random sampling was employed whereby students were categorized into schools and selected proportionately. In addition, students were proportionately selected by sex.

Data was collected using two methods which are literature review and questionnaires. Through literature review, previous researches related to the subject matter were reviewed to establish what others have documented on the subject matter. Useful information was collected from seminar and workshop papers, journal papers and internet sources. A self-administered questionnaire for ARU students was used for determining attitude and socio-demographic aspects pertinent to HIV and AIDS. The study adopted standard questionnaires developed by UNAIDS, Family Health International (FHI) and Demographic and Health Surveys (DHS). The major variables were background and altitudes towards HIV and AIDS. Background variables included sex, marital status, school, religion, residence and sponsor. Altitude indicators were readiness to share a meal with HIV/AIDS person, willingness to share reading materials with HIV/AIDS person, whether HIV positive lecturer should continue to teach, willingness to buy stationery from HIV infected person, willingness to buy vegetables from an AIDS infected seller, willingness to reveal HIV status to family member, whether unmarried women should always be able to buy condoms, whether one has ever tested for HIV, whether one has ever told anyone about the HIV results, if tested whether one would wish to test again, and, willingness of one to disclose personal HIV test results to anyone. Six Hundred Twenty Five (625) questionnaires were distributed to students in various programmes out of which 391 were fairly filled equating to $62.6 \%$. Collected data was coded and all the mistakes that occurred during data entry process in SPSS software package version 20.0 were identified, corrected and the data was analyzed.

\section{Results}

Descriptive statistics, recode into different variables and compute variables features of SPSS were used to compute frequencies for background variables, attitude index and scale for attitude index. The attitude index was developed to determine the extent to which various variables can be grouped together into a smaller number of indicators which summarizes the linear relationship between those variables. The score of variables are set between 1 and 0 . The number of variables selected for developing the attitude index is 11 . The index scale used for this study is between 0 and 11 as shown in Table 1. To develop the scale for attitude index, a median of 11 variables was calculated which is 5 and defined into score ranges as follows: 0-4 =Negative attitude, $5=$ Neutral attitude and 6 and above $=$ positive attitude. In calculating the scale for index new score ranges were redefined as Lowest through $4=1,6$ through Highest $=3$ and $\mathrm{ELSE}=2$ 
Table 1. Attitude index

\begin{tabular}{|c|c|c|c|c|}
\hline $\mathrm{S} / \mathrm{N}$ & Attitude indicator & Variable & Frequency & $\%$ \\
\hline A1 & Ever shared a meal with HIV and AIDS person & 0 & 24 & 6.1 \\
\hline A2 & $\begin{array}{l}\text { Willingness of sharing reading materials or be in a discussion group with a HIV } \\
\text { infected student }\end{array}$ & & 5 & 1.3 \\
\hline A3 & $\begin{array}{l}\text { Whether HIV positive lecturer should be allowed to continue teaching in the } \\
\text { University }\end{array}$ & & 4 & 1.0 \\
\hline A4 & Willingness to buy stationeries from an AIDS infected vendor & 3 & 17 & 4.3 \\
\hline A5 & Willingness to buy vegetables from an AIDS infected seller & 4 & 37 & 9.5 \\
\hline A6 & Willingness to reveal HIV and AIDS status of the infected family member & 5 & 50 & 12.8 \\
\hline A7 & whether unmarried women should be allowed to buy condoms & 6 & 81 & 20.7 \\
\hline A8 & Have you ever had HIV test? & 7 & 76 & 19.4 \\
\hline A9 & Whether one told anyone about the results of the test & 8 & 45 & 11.5 \\
\hline A10 & If you ever tested would you ever want to be tested (again) for HIV? & 9 & 41 & 10.5 \\
\hline A11 & $\begin{array}{l}\text { If you chose to be tested for HIV, the virus that causes AIDS, and were told after the } \\
\text { test that you had HIV, would you tell anyone the results }\end{array}$ & & 11 & 2.8 \\
\hline & Total & & 391 & 100 \\
\hline
\end{tabular}

\subsection{Background Characteristics of Respondents}

Table 2 presents background characteristics of the respondents. Students background presented are: demographic and socio-economic features. The students' demographic characteristics include sex, age, and marital status while students' socio-economic characteristics are school, religion, residence and sponsorship status. Results indicate that $63.9 \%$ male and $36.1 \%$ female participated in the study. Age wise, the data was classified into five-year age groups. The results revealed that to both male and female the majority of the students $(86.8 \%)$ are in age group 20 to 24 years. The age range for both male and female was 13 years. The mean age revealed that male are slightly older (21.8 years) than female (20.8). As expected, most of the students are single (94.1\%). Very few students are married (2.3\%). Students' socio-economic characteristics of school, religion, residence and sponsorship status are summarized in Table 1. Regarding schools, majority of the students were from SRES $(29.2 \%)$ followed by SEST (20.7\%). SADE had the least number of respondents (7.7\%). As regards to religion, majority were Christians of Roman Catholic denomination (40.2\%) followed by other Christians (37.1\%). There was a slight difference between off-campus and in-campus students. As expected majority of off-campus students were male (39.2\%) compared to their female counterparts $(11.9 \%)$. As anticipated the majority of the students $(64.5 \%)$ were sponsored by Higher Education Student Loan Board (HESLB). 
Table 2. Demographic and socio-economic characteristics of the respondents

\begin{tabular}{|c|c|c|c|}
\hline Variable & Female $(n=141)$ & Male $(n=250)$ & Total $(n=391)$ \\
\hline \multicolumn{4}{|l|}{ Age } \\
\hline 15 to 19 & $5.5 \%$ & $1.3 \%$ & $6.9 \%$ \\
\hline 20 to 24 & $29.8 \%$ & $57.0 \%$ & $86.8 \%$ \\
\hline 25 to 29 & $.8 \%$ & $4.5 \%$ & $5.3 \%$ \\
\hline 30 to 34 & $.5 \%$ & $.5 \%$ & $1.1 \%$ \\
\hline \multicolumn{4}{|l|}{ Marital status $(\mathrm{n}=388)$} \\
\hline Married & $1.0 \%$ & $1.3 \%$ & $2.3 \%$ \\
\hline Separated/ Divorced & $.8 \%$ & $1.0 \%$ & $1.8 \%$ \\
\hline Living together & $.8 \%$ & $1.0 \%$ & $1.8 \%$ \\
\hline Single & $33.5 \%$ & $60.6 \%$ & $94.1 \%$ \\
\hline \multicolumn{4}{|l|}{ School $(n=391)$} \\
\hline SADE & $2.6 \%$ & $5.1 \%$ & $7.7 \%$ \\
\hline SCEM & $6.6 \%$ & $9.2 \%$ & $15.9 \%$ \\
\hline SEST & $6.4 \%$ & $14.3 \%$ & $20.7 \%$ \\
\hline SGST & $4.1 \%$ & $5.6 \%$ & $9.7 \%$ \\
\hline SRES & $10.0 \%$ & $19.2 \%$ & $29.2 \%$ \\
\hline SURP & $6.4 \%$ & $10.5 \%$ & $16.9 \%$ \\
\hline \multicolumn{4}{|l|}{ Religion $(\mathrm{n}=388)$} \\
\hline $\mathrm{RC}$ & $17.0 \%$ & $23.2 \%$ & $40.2 \%$ \\
\hline Muslim & $4.6 \%$ & $15.5 \%$ & $20.1 \%$ \\
\hline Other Christian & $13.7 \%$ & $23.5 \%$ & $37.1 \%$ \\
\hline Traditional & $.3 \%$ & $.8 \%$ & $1.0 \%$ \\
\hline 0ther religion & $.8 \%$ & $.8 \%$ & $1.5 \%$ \\
\hline \multicolumn{4}{|l|}{ Residence $(n=388)$} \\
\hline In campus & $24.2 \%$ & $24.7 \%$ & $49.0 \%$ \\
\hline Off campus & $11.9 \%$ & $39.2 \%$ & $51.0 \%$ \\
\hline \multicolumn{4}{|l|}{ Sponsor $(\mathrm{n}=386)$} \\
\hline HESLB & $20.2 \%$ & $44.3 \%$ & $64.5 \%$ \\
\hline Parent/Guardian & $15.8 \%$ & $17.4 \%$ & $33.2 \%$ \\
\hline Spouse & $.0 \%$ & $.5 \%$ & $.5 \%$ \\
\hline Self-sponsored & $.5 \%$ & $1.3 \%$ & $1.8 \%$ \\
\hline Total & $36.1 \%$ & $63.9 \%$ & 100 \\
\hline
\end{tabular}

SADE $=$ School of Architecture and Design; SCEM=School of Construction Economics and Management; SEST= School of Environmental Science and Technology; SGST= School of Geospatial Science and Technology; SURP = School of Urban and Regional Planning and SRES=School of Real Estate Studies

\subsection{Students' General Attitude towards HIV and AIDS}

Table 3 presents general attitude of respondents towards people living with HIV and AIDS and other attitudinal issues. Attitudes toward HIV and AIDS for all respondents were computed based on attitude index, attitude scale and redefined score ranges. Results reveal that there are elements of stigma and discrimination among students as 
more than a fifth (22.3\%) have indicated negative attitude towards HIV and AIDS. There is also a trace of neutral attitude which accounts to $12.8 \%$ of respondents.

Table 3. Overall students' attitude towards HIV and AIDS

\begin{tabular}{llll}
\hline $\mathbf{S} / \mathbf{N}$ & Attitude indicator & Frequency & $\mathbf{\%}$ \\
\hline 1 & Negative Attitude & 87 & 22.3 \\
2 & Neutral Attitude & 50 & 12.8 \\
3 & Positive Attitude & 254 & 65.0 \\
\hline Total & & $\mathbf{3 9 1}$ & $\mathbf{1 0 0 . 0}$ \\
\hline
\end{tabular}

\subsection{Gender and Attitude towards HIV and AIDS}

Table 4 presents disaggregated data on attitude towards HIV and AIDS. This part aims to establish if attitude towards HIV and AIDS based on the sex of respondents. Results reveal that slightly more female $(65.2 \%)$ had positive altitude than male (64.8\%). Likewise, female maintained a neutral attitude (14.2\%) compared to male $(12 \%)$. Further analysis using Pearson Chi-Square indicates that there is no significant difference between female and male attitudes towards HIV and AIDS as shown in Table 5.

Table 4. Attitude towards HIV and AIDS and sex of the respondent

\begin{tabular}{|c|c|c|c|c|c|}
\hline & & & \multicolumn{2}{|c|}{ Sex of the Respondent } & \multirow{2}{*}{ Total } \\
\hline & & & Female & Male & \\
\hline \multirow{7}{*}{$\begin{array}{l}\text { Scale of attitude towards } \\
\text { HIV and AIDS }\end{array}$} & \multirow{2}{*}{ Negative Attitude } & Count & 29 & 58 & 87 \\
\hline & & $\%$ within Sex of the Respondent & $20.6 \%$ & $23.2 \%$ & $22.3 \%$ \\
\hline & \multirow[b]{2}{*}{ Neutral Attitude } & Count & 20 & 30 & 50 \\
\hline & & $\%$ within Sex of the Respondent & $14.2 \%$ & $12.0 \%$ & $12.8 \%$ \\
\hline & \multirow{3}{*}{ Positive Attitude } & Count & 92 & 162 & 254 \\
\hline & & $\%$ within Sex of the Respondent & $65.2 \%$ & $64.8 \%$ & $65.0 \%$ \\
\hline & & $\%$ of Total & $23.5 \%$ & $41.4 \%$ & $65.0 \%$ \\
\hline \multirow[b]{2}{*}{ Total } & & Count & 141 & 250 & 391 \\
\hline & & $\begin{array}{l}\% \text { within Scale of attitude towards HIV } \\
\text { and AIDS }\end{array}$ & $36.1 \%$ & $63.9 \%$ & $100.0 \%$ \\
\hline
\end{tabular}

Table 5. Chi-Square Tests

\begin{tabular}{lllc}
\hline & Value & df & Asymp. Sig. (2-sided) \\
\hline Pearson Chi-Square & $.620^{\mathrm{a}}$ & 2 & .733 \\
Likelihood Ratio & .618 & 2 & .734 \\
Linear-by-Linear Association & .124 & 1 & .725 \\
N of Valid Cases & 391 & & \\
\hline
\end{tabular}

\subsection{Attitude towards HIV and AIDS across Schools}

Table 6 presents data on attitude towards HIV and AIDS basing on school of respondents. This part aims to establish if attitude towards HIV and AIDS is influenced by the nature of courses studied by respondents. Across schools negative attitude towards HIV and AIDS was apparent within schools. The School of Architecture and Design has the highest percentage of negative altitude (26.7\%) and the least positive (46.7\%). On the other hand, SURP has the least percentage of negative altitude (16.7\%) and the highest positive attitude $(78.8 \%)$. Further 
analysis using Pearson Chi-Square indicates that there is a significant difference across schools on attitudes towards HIV and AIDS as shown in Table 7.

Table 6. Attitude towards HIV and AIDS and the school of respondents

\begin{tabular}{|c|c|c|c|c|c|c|c|c|c|}
\hline & & & \multicolumn{6}{|c|}{ The School of Respondent at ARU } & \multirow{2}{*}{ - Total } \\
\hline & & & SADE & SCEM & SEST & SGST & SRES & SURP & \\
\hline \multirow{6}{*}{$\begin{array}{l}\text { Scale of attitude } \\
\text { towards HIV and } \\
\text { AIDS }\end{array}$} & \multirow{2}{*}{$\begin{array}{l}\text { Negative } \\
\text { Attitude }\end{array}$} & Count & 8 & 10 & 21 & 9 & 28 & 11 & 87 \\
\hline & & $\begin{array}{l}\% \text { within The School of } \\
\text { Respondent at ARU }\end{array}$ & $26.7 \%$ & $16.1 \%$ & $25.9 \%$ & $23.7 \%$ & $24.6 \%$ & $16.7 \%$ & $22.3 \%$ \\
\hline & \multirow{2}{*}{$\begin{array}{l}\text { Neutral } \\
\text { Attitude }\end{array}$} & Count & 8 & 13 & 9 & 5 & 12 & 3 & 50 \\
\hline & & $\begin{array}{l}\% \text { within The School of } \\
\text { Respondent at ARU }\end{array}$ & $26.7 \%$ & $21.0 \%$ & $11.1 \%$ & $13.2 \%$ & $10.5 \%$ & $4.5 \%$ & $12.8 \%$ \\
\hline & \multirow{2}{*}{$\begin{array}{l}\text { Positive } \\
\text { Attitude }\end{array}$} & Count & 14 & 39 & 51 & 24 & 74 & 52 & 254 \\
\hline & & $\begin{array}{l}\% \text { within The School of } \\
\text { Respondent at ARU }\end{array}$ & $46.7 \%$ & $62.9 \%$ & $63.0 \%$ & $63.2 \%$ & $64.9 \%$ & $78.8 \%$ & $65.0 \%$ \\
\hline \multirow[t]{2}{*}{ Total } & & Count & 30 & 62 & 81 & 38 & 114 & 66 & 391 \\
\hline & & $\begin{array}{l}\% \text { within Scale of attitude } \\
\text { towards HIV and AIDS }\end{array}$ & $7.7 \%$ & $15.9 \%$ & $20.7 \%$ & $9.7 \%$ & $29.2 \%$ & $16.9 \%$ & $100.0 \%$ \\
\hline
\end{tabular}

Table 7. Chi-Square Tests

\begin{tabular}{llll}
\hline & Value & df & Asymp. Sig. (2-sided) \\
\hline Pearson Chi-Square & $18.537^{\mathrm{a}}$ & 10 & .047 \\
Likelihood Ratio & 18.320 & 10 & .050 \\
Linear-by-Linear Association & 2.745 & 1 & .098 \\
N of Valid Cases & 391 & &
\end{tabular}

a. 2 cells (11.1\%) have expected count less than 5 . The minimum expected count is 3.84 .

\section{Discussion}

In this study more male students participated than their female counterparts which is in consistence with the studies of Zhang et al. (2008), Masoudnia (2015) and Kuete et al. (2016). However, this is contrary to the previous works of Lau \& Tsui (2005), Lohmann et al. (2009), Movahed and Shoaa (2010), Rahnama et al. (2011), Kopele \& Shumba (2011) and Amo-Adjei \& Darteh (2013) where more female participated in the study than male. In the case of this study, participation of more male than female was influenced by the respondents selection method used and the number of female students admitted at the University. In terms of age, majority of both male and female was in the age group 20 to 24 years the same as the research done by Zhang et al. (2008). The participation of schools was such majority of the students was from SRES followed by SEST, and SADE had the least number of respondents.

Negative attitude towards HIV and AIDS is a setback to HIV prevention efforts. Negative attitude still exists among students as more than a fifth of respondents in this study have indicated negative attitude towards HIV and AIDS. This finding is consistent with findings of previous studies of Tavoosi et al. (2004), Unnikrishnan et al. (2010), Rahnama et al. (2011), Movahed \& Shoaa (2010) and Kopele \& Shumba (2011). This implies that a good number of students stigmatize and discriminate people living with HIV and AIDS. Similarly, students responded negatively to other stigma and discriminatory indicators.

Differences in attitude towards HIV and AIDS between male and female respondents were determined in various studies. In this study slightly more female than male had positive attitude towards HIV and AIDS. Tavoosi et al. (2004), Amo-Adjei \& Darteh (2013) and Movahed \& Shoaa (2010) report that negative attitude towards HIV and 
AIDS, stigma and discrimination are apparent in male than female. Equally, a study by Lau \& Tsui (2005) reveal more negative attitude towards HIV and AIDS of male in two items out of three than female. However, this finding together with previous studies contradicts the results of the study by Masoudnia (2015) who determines that discriminatory attitudes toward PLWHA were higher in women than men. Despite these stances, further analysis using Pearson Chi-Square reveals that there was no significant difference between female and male attitudes towards HIV and AIDS.

The University has six schools and respondents were selected from all schools. Surprisingly, negative attitude towards HIV and AIDS was apparent within schools. SADE has the highest number of respondents with negative attitude and the least with positive attitude towards HIV and AIDS. On the other hand, SURP has the least number of respondents with negative attitude and the highest positive attitude towards HIV and AIDS. This finding is supported by Movahed \& Shoaa (2010) study which found that the field of study was among the factors influencing students' attitude towards HIV and AIDS. This may be attributed by the nature of courses they study that is social science for SURP and pure/applied science for SADE. Further analysis carried out using Pearson Chi-Square reveal that there was a significant difference across schools on attitudes towards HIV and AIDS.

\section{Conclusions}

Attitude towards HIV and AIDS is an important factor in gauging levels of stigma and discrimination. Studies reviewed disclose negative attitude towards PLWHA in varying aspects at considerable levels. The present study also concludes that significant levels of stigma and discrimination against PLWHA still exist among students. Among groups that exhibited negative attitude towards HIV and AIDS male were on the fore front comparing to female counterparts though the difference was not statistically significant. Likewise, across the schools, SADE dominated on the number of students who have negative attitude towards HIV and AIDS and the difference across all the schools was statistically significant. In view of the findings from this study, it is high time for the university to:

- Periodically sensitize students on the consequences of stigma and discrimination to PLWHA through workshop and seminars

- Prepare and distribute leaflets on positive and negative attitude towards HIV and AIDS

- Guide students to devise health programmes and groups that among that deal with HIV and AIDS related issues such as outreach programmes using peer educators, and, formation of students' health clubs and associations.

\section{Ethical Considerations}

The study was given ethical clearance by the University's Directorate of Postgraduate Studies, Research and Publications to carry out the study as well as engage the University students as respondents. The study was of anonymous nature and consent from the respondents was also requested by the Researchers in form of a small note attached in the self-administered questionnaires. The respondents were clearly informed of the objective of the research as well as assured of the confidentiality of the answers as being meant for research purpose only. No identifying information was contained in the questionnaire. The returning of a completed questionnaire indicated approval of participation in the study. The participation in the survey was totally voluntary. Participants had the option of declining to answer specific questions or leaving the entire questionnaire blank if they wished to. However, respondents were requested fully fill in the questionnaire and provide genuine answers if they are to participate.

\section{Competing Interests Statement}

The authors declare that there is no conflict of interests regarding the publication of this paper.

\section{References}

Amo-Adjei, J., \& Darteh, E. K. M. (2013). Drivers of Young People's Attitudes towards HIV/AIDS Stigma and Discrimination: Evidence from Ghana. African Journal of Reproductive Health December 2013 (Special Edition on HIV/AIDS), 17(4), 51-59. Retrieved 29 September, 2016, from https://www.ajol.info/index.php/ajrh/article/viewFile/99725/89004

East Africa Community (EAC) /AMREF Lake Victoria Partnership (EALP). (2010). HIV Sero-Behavioural Study in Six Universities in Tanzania, Study Report, November 2010 Study.

Hayyawi, A. H., Al-Marayaty, A. Y, Salman, W. S., \& Hamed, W. (2010). HIV/AIDS knowledge, attitudes and beliefs among a group of Iraqis. Eastern Mediterranean Health Journal, 16(1), 18-23. Retrieved 29 Septemberm 2016, from https://www.researchgate.net/profile/ALI_H_Hayyawi/publication/41847396 
Katahoire, A. R., \& Kirumira, E. K. (2008). The impact of HIV and AIDS on higher education institutions in Uganda. International Institute of education planning. Retrieved 15 July, 2011, from http://hivhealthclearinghouse.unesco.org/sites/default/files/resources/Uganda\%20HIV-AIDS\%20secured.pd $\mathrm{f}$

Kopele, B., \& Shumba, A. (2011). Sexual Behaviours and Attitudes towards Safer Sex of Psychology Students at a South African University Campus. Anthropologist, 13(4), 257-264.

Kuete, M., Qiao Huang, Q., Abid Rashid, A., Ma, X. L, Yuan, H. F, Antezana, J. P. E., \& Zhang, H. P. (2016). Differences in Knowledge, Attitude, and Behavior towards HIV/AIDS and sexually transmitted infections between sexually active foreign and Chinese medical students. https://doi.org/10.1155/2016/4524862

Lau, J. T. F., \& Tsui, H. Y. (2004). Discriminatory attitudes towards people living with HIV/ AIDS and associated factors: A population based study in the Chinese general population. Sex Transm Infect, 81, 113-119. http://doi:10.1136/sti.2004.011767

Lohmann, T., Tam, P., Hopman, W. M., \& Wobeser, W. (2009). Knowledge of and attitudes towards HIV/AIDS among school teachers in Belize. International Journal of Infectious Diseases, 13, e228-e23. https://doi.org/10.1016/j.ijid.2008.11.023

Masoudnia, E. (2015). Public perceptions about HIV/AIDS and discriminatory attitudes toward people living with acquired immunodeficiency syndrome in Iran. SAHARA-J: Journal of Social Aspects of HIV/AIDS, 12(1), 116-122. http://doi:10.1080/17290376.2015.1123644

Movahed, M., \& Shoaa, S. (2010). On attitude towards HIV/AIDS among Iranian students (Case Study: High School Students in Shiraz City). Pakistan Journal of Biological Sciences, 13(6), 271-278. https://doi.org/10.3923/pjbs.2010.271.278

Rahnama, R., Rampal, L., Lye, M., \& Rahman, H. A. (2011). Factors influencing students' attitude towards HIV/AIDS in a public university, Malaysia. Global Journal of Health Science, 3(1), 128-134. https://doi.org/10.5539/gjhs.v3n1p128

Ranjan, A., Babu, G. R., \& Detels, R. (2015). Knowledge, Attitude and Perception about HIV/AIDS among the Wives of Migrant Workers of Muzaffarpur District in Bihar. J Community Med Health Educ, 5, 361. https://doi.org/10.4172/2161-0711.1000361

Sample Size Calculator. Retrieved 13 March, 2011 from www.surveysystem.com

Tanzania Commission for AIDS (TACAIDS), Zanzibar AIDS Commission (ZAC), National Bureau of Statistics (NBS), Office of the Chief Government Statistician (OCGS), and ICF International. (2013). Tanzania HIV/AIDS and Malaria Indicator Survey 2011-12. Dar es Salaam, Tanzania: TACAIDS, ZAC, NBS, OCGS, and ICF International.

Tavoosi, A., Zaferani, A., Enzevaei, A., Tajik, P., \& Ahmadinezhad, Z. (2004). Knowledge and attitude towards HIV/AIDS among Iranian students. BMC Public Health, 17. https://doi.org/10.1186/1471-2458-4-17

UNAIDS Fact Sheet. (2015). Retrieved 4 December, 2015, from www.unaids.org/en/resources

UNAIDS Fact Sheet. (2016). Retrieved 16 November, 2016, from http://www.unaids.org/en/resources/fact-sheet

Unnikrishnan, B, Mithra, P. P., Rekha, T., \& Reshmi, B. (2010). Awareness and attitude of the general public toward HIV/AIDS in coastal Karnataka. Indian $J$ Community Med [serial online], 2(35), 142-146 https://doi.org/10.4103/0970-0218.62580

URT. (2013). Tanzania Third National Multi-Sectoral Strategic Framework for HIV and AIDS (2013/14-2017/18). Retrieved 5 December, 2016, from http://tacaids.go.tz

Zhang, L., Li, X., Mao, R., Stanton, B., Zhao, Q., Wang, B., \& Mathur, A. (2008). Stigmatizing attitudes towards people living with HIV/AIDS among college students in China. Health Education, 108(2), 130-144. http://dx.doi.org/10.1108/09654280810855586

\section{Copyrights}

Copyright for this article is retained by the author(s), with first publication rights granted to the journal.

This is an open-access article distributed under the terms and conditions of the Creative Commons Attribution license (http://creativecommons.org/licenses/by/4.0/). 